\title{
O CONSUMO NAS COMUNIDADES DE BAIXA RENDA E A POSSE NAS AÇÕES DE USUCAPIÃO COLETIVA.
}

\author{
GUILHERME MAGALHÃES MARTINS ${ }^{1}(*)(* *)$
}

\begin{abstract}
RESUMO:
O trabalho busca traçar os contornos do Alcance da usucapião coletiva prevista pelo o artigo 10 do Estatuto da Cidade, abordando a interface entre este diploma e o Código de Defesa do Consumidor e considerando o consumo nas favelas como critério para a verificação da posse ad usucapionem.
\end{abstract}

PALAVRAS-CHAVE: Usucapião Coletiva; Consumo; Favelas; Posse.

\begin{abstract}
:
The paper seeks to outline the range of collective prescription provided by Article 10 of the Statute of the City, addressing the interface between this law and the Code of Consumer Rights and considering consumption in the slums as a criterion for verifying possession ad usucapionem.
\end{abstract}

KEYWORDS: Adverse Possession Collective; Consumption; Slums; Posse.

\section{1-Introdução}

Uma das características mais marcantes do direito pós-moderno é o pluralismo, que se manifesta na multiplicidade de fontes legislativas a regular o mesmo fato e na variada gama de sujeitos a proteger (menores, consumidores, locatários e possuidores de baixa renda), identificados como os mais fracos na sociedade e merecedores de tratamento diferenciado.

Essa pluralidade de fontes e de agentes fracos a proteger aparece, nas palavras de Erik Jayme, unida ao renascimento dos direitos humanos e valoração dos direitos fundamentais, contrapondo-se à globalização e às regras de mercado. ${ }^{2}$

\footnotetext{
${ }^{1}$ Promotor de Justiça no Estado do Rio de Janeiro. Doutor e Mestre em Direito Civil pela UERJ. Professor adjunto de Direito Civil da Faculdade Nacional de Direito-UFRJ e da Universidade Candido Mendescentro(licenciado).Professor visitante(2009-2010) do Mestrado em Direito Civil da Faculdade de Direito da UERJ. O autor registra seu agradecimento ao acadêmico Ricardo Salgado Gomes, bolsista de iniciação científica da Faculdade de Direito da UERJ, pelo auxílio à pesquisa realizada.

Visões para uma teoria pós-moderna do direito comparado. Cadernos do Programa de Pós-Graduação em Direito da UFRGS. 2.ed. Tradução Claudia Lima Marques. Porto Alegre, v.1., n ${ }^{\circ}$ 1, p.120, mar.2003: "O saber, a condição pós-moderna não é somente um instrumento de poder. Ele desenvolve, refina nossa sensibilidade para as diferenças e reforça nossa capacidade de suportar o incomensurável, o inconciliável(...)Pensado é aqui não só a pequena autonomia dos indivíduos, mas sim significa a convivência, lado a lado, ao mesmo tempo, dos diferentes, do estrangeiro(...), é a adaptação dos contrapostos. Comparação pós-moderna significa então estudar a posição dos vários sistemas jurídicos nestas questões”.
} 
Devem ser compreendidos, dentro dessa nova ordem, o Estatuto da Cidade e os novos instrumentos jurídicos como meio de concreção de normas constitucionais, dos princípios fundantes do sistema e dos direitos fundamentais da pessoa. No mesmo sentido atua o respeito às diversidades, que tecem o modelo de cidade contemporânea e nela consolidam os direitos fundamentais. $^{3}$

Em artigo visionário, muito anterior à aprovação da Lei $\mathrm{n}^{\circ} 10.257 / 01$ e à recente explosão das favelas em todo o país, como conseqüência do êxodo rural e do inchaço urbano, Dalmo de Abreu Dallari ${ }^{4}$ já defendia a usucapião coletiva, com base na proteção jurídica da posse de áreas em situação de abandono, por quem dela necessita ou lhe dá utilidade social:

Nas modernas Constituições vem sendo dada ênfase cada vez maior à significação jurídica da destinação efetiva e imediata do imóvel, ao contrário da orientação positivista que atribuía valor absoluto ao título formal e abstrato sem indagar da situação concreta. O crescimento das populações, a necessidade de aumentar a produção de alimentos, a trágica situação em que vivem milhões de pessoas completamente amontoadas ou completamente desabrigadas nas grandes cidades, tudo isso exige que se dê a terra, urbana ou rural, a utilização mais conveniente às necessidades das sociedades humanas.

O Estatuto da Cidade disciplinou duas modalidades de usucapião, com características próprias e inconfundíveis entre si: a usucapião individual (art. $9^{\circ}$.) e o usucapião coletivo (art.10).

A usucapião individual tem a finalidade precípua de regularização da situação fundiária da população de baixa renda e de concretização da norma do artigo 183 da Constituição da República. $^{5}$

Já à usucapião coletiva incumbe dupla tarefa: além de regularizar a situação fundiária, permitir a ocupação de áreas ocupadas por população de baixa renda, alterando o velho perfil socialmente indesejável de núcleos habitacionais urbanos como as favelas.

As favelas, devido à expansão da economia, inicialmente informal e depois até mesmo formal, passam a ser grandes centros de negócios e serviços em geral, o que contribui para a fixação dos possuidores ao solo urbano. Mais do que favelados, seus moradores passam a ser tratados como consumidores, tornando-se alvo de um mercado cada vez mais aquecido.

3 GOMES, Rosângela Maria de Azevedo. A usucapião coletiva: uma análise crítica do art. 10 da Lei $\mathrm{n}{ }^{\circ}$ 10.257 de 2001(Estatuto da Cidade).In: TEPEDINO, Gustavo; FACHIN, Luiz Edson. O Direito \& O Tempo; embates jurídicos e utopias contemporâneas . Rio de Janeiro: Renovar, 2008. p.712.

$4 \quad$ Usucapião coletivo. Revista de Informação Legislativa. Brasília, n ${ }^{\circ}$ 115, p.375, jul./set.1992. No entanto, o usucapião coletivo, como previsto no Estatuto da Cidade, não se limita aos casos de composse, como defendido pelo autor.

5 LOUREIRO, Francisco Eduardo. Usucapião individual e coletivo no Estatuto da Cidade. Revista Trimestral de Direito Civil. Rio de Janeiro, v.9, p.29, jan./mar. 2002 
Assim como a usucapião coletiva do Estatuto da Cidade, o sistema da Lei $n^{\circ}$ 8078/90 foi construído para o fim especial de proteger os vulneráveis, os diferentes, os mais fracos, e sua origem constitucional deve ser a guia de sua interpretação: um direito do consumidor efetivo, que concretize direitos humanos, direitos fundamentais, para o mais fraco que mereceu esta tutela especial constitucional, em especial o consumidor pessoa física. ${ }^{6}$

Na obra de Erik Jayme, destaca-se, em face do atual pluralismo pós-moderno, de um direito com fontes legislativas plúrimas, a necessidade de coordenação entre as leis de um mesmo ordenamento, como exigência para um sistema jurídico eficiente e justo. A expressão diálogo das fontes expressa a necessidade de uma aplicação coerente das leis de direito privado, co-existentes no sistema. ${ }^{7}$

Através do diálogo entre ambos os diplomas, tendo como vértice a dignidade da pessoa humana e a solidariedade social erigidas em valores fundamentais do ordenamento civilconstitucional, busca-se uma solução que ajude a operacionalizar a usucapião coletiva, através da legalização da "cidade ilegal". 8

$6 \quad$ MARQUES, Claudia Lima. Contratos no Código de Defesa do Consumidor. 4.ed. São Paulo: Revista dos Tribunais, 2004. p.313.

7 MARQUES, Claudia Lima. Diálogo das Fontes. In: BENJAMIN, Antônio Herman; ; BESSA, Leonardo Roscoe. Manual de Direito do Consumidor. São Paulo: Revista dos Tribunais, 2008.p.87-88. A autora cita a seguinte passagem do voto do Ministro Joaquim Barbosa no julgamento da ADIN 2591, que concluiu pela constitucionalidade da aplicação do Código de Defesa do Consumidor a todas as atividades bancárias, reconhecendo a necessidade atual do diálogo das fontes: "Entendo que o regramento do sistema financeiro e a disciplina do consumo e da defesa do consumidor podem perfeitamente conviver. Em muitos casos, o operador do direito irá deparar-se com fatos que conclamam a aplicação de normas tanto de uma como de outra área do conhecimento jurídico. Assim ocorre em razão dos diferentes aspectos que uma mesma realidade apresenta, fazendo com que ela possa amoldar-se aos âmbitos normativos de diferentes leis(...)" E prossegue: "não há que se falar em exclusão formal entre essas espécies normativas, mas sim em influências recíprocas, em aplicação conjunta das duas normas ao mesmo tempo e ao mesmo caso, seja complementarmente, seja subsidiariamente, seja permitindo a opção voluntária das partes sobre a fonte prevalente".

8 Para Carlos Ari Sundfeld, as relações entre urbanismo e pobreza oscilam entre o desprezo mútuo e o conflito, visto que "a impossibilidade de largas camadas da população terem acesso à propriedade vem sendo tratada como um problema apenas econômico, sem solução específica no campo urbanístico - como se a 'ordem urbanística 'somente fosse possível na abundância. Por óbvio, o mesmo urbanismo elitista que ignora a pobreza é ignorado por ela. O solo urbano passa a ser objeto de ações clandestinas (invasão de imóveis públicos e de espaços comuns, construções irregulares, ocupação de glebas não urbanizadas e de áreas protegidas) e de relações informais (transações de 'posses', instalação de serviços e equipamentos públicos em favelas etc.). O resultado é a anemia do direito urbanístico, enredado na contradição entre cidade legal e cidade ilegal.

O Estatuto da Cidade constitui a primeira tentativa de resposta jurídica abrangente a esse impasse, por meio da instituição de um direito urbanístico popular. Ele resulta da adoção de duas orientações convergentes; por um lado, a transferência dos grupos marginalizados para dentro do mundo jus-urbanístico(pela criação de novos instrumentos para o acesso à propriedade formal, bem como de medidas para a regularização fundiária urbana e para a regularização das urbanizações clandestinas)e, por outro, a adequação da ordem urbanística à situação real da população, por meio de meio de normas especiais de urbanização(ordem urbanística popular). SUNDFELD, Carlos Ari. O Estatuto da Cidade e suas Diretrizes Gerais. In: DALLARI, Adilson Abreu; FERRAZ, Sérgio. Estatuto da Cidade; comentários à Lei Federal 10.257/2001. São Paulo: Malheiros, 2003. p.58. 
Trata-se de uma antítese que envolve, segundo a visão tradicional, as ordens formal e informal, tendo de um lado a cidade do "asfalto", que obedece aos cânones de respeito ao direito de propriedade e às regras de urbanismo, e do outro a cidade da "favela", que supostamente invade a propriedade privada e ignora a ordem urbanística. ${ }^{9}$

Uma boa parte da população das cidades parece condenada a uma condição de subcidadania, de modo que "a irregularidade jurídico-urbanística da ocupação serve como uma espécie de 'escudo', para justificar o abandono dos territórios 'fora-da-lei' pelo Poder Público". ${ }^{10}$

No cenário urbano, mostra-se gritante o imenso contraste entre a ordem legalmente estabelecida e a realidade das coisas, ao passo que a função social da propriedade ${ }^{11}$ e os valores fundamentais do ordenamento devem impedir a exclusão da multidão dos favelados do mundo da vida e da cidadania. ${ }^{12}$

A vulnerabilidade, princípio basilar da Política Nacional das Relações de Consumo (art. $4^{\circ}$, I, Lei $\mathrm{n}^{\circ}$ 8078/90), pode dialogar com as diretrizes gerais da política urbana, visando,

$9 \quad$ LOUREIRO, op.cit, p.40

10 ALFONSIN, Betânia. O significado do Estatuto da Cidade para os processos de regularização fundiária no Brasil. In: Regularização fundiária plena; referências conceituais. Brasília: Ministério das Cidades, 2007. p.71-72.

11 Comentando ação civil pública movida pelo Ministério Público do Estado de São Paulo em face do Município de São Paulo, para o fim de ver reconhecida concessão de direitos reais de uso na região situada no Parque Novo Amaro, afirma Roberto Correia da Silva Gomes Caldas: “(...)o desenvolvimento de tal tese teve sua influência, em grande parte, pelo fato de que foram postos à disposição dos moradores, pelo Poder Público Municipal, todos os serviços inerentes à infra-estrutura urbana, conforme dito acima, tais como os de fornecimento de água encanada, coleta e tratamento de esgoto, iluminação pública e particular, coleta de lixo, transporte público, pavimentação de ruas e atribuição de códigos de endereçamento postal, bocas-de-lobo para coleta de águas fluviais, calçamento, telefonia pública e particular, serviços de correios e telégrafos etc., para lhes conferir o mínimo de dignidade(em sua maioria, trabalhadores que sobrevivem de renda ínfima), vez que vítimas da injusta e desumana situação de desigualdade socioeconômica do País. Essa atitude do Município de São Paulo, ao longo de tanto tempo, teve o condão de evidenciar o seu reconhecimento de que a função social precípua de tal propriedade é a de servir de base para a construção de moradias da população de baixa renda que ali se instalou, bem como a sua aquiescência com essa ocupação. $\mathrm{E}$ isso porque, ao permitir e consentir que durante décadas os moradores ali residissem, prestando a eles os serviços públicos básicos mencionados acima(...), e demais outros comuns a todo e qualquer bairro devidamente urbanizado, o Município de São Paulo firmou mais que um mero reconhecimento, mas um verdadeiro acordo com os mesmos, propositalmente tácito"'(g.n.). CALDAS, Roberto Correia da Silva Gomes. O fenomeno da legalização das favelas e sua transmutação em concessões públicas. Interesse Publico, Porto Alegre, v. 8, n.37,p. 323-325, maio/jun. 2006.

12 POGREBINSCHI, Thamy. A questão fundiária na Favela da Rocinha. Revista Trimestral de Direito Civil. Rio de Janeiro, v.9, p.241, jan./mar.2002. A matéria é polêmica, valendo transcrever vozes autorizadas, como a de José Carlos Moraes e Salles, de quem ousamos discordar: "A meta do poder público deveria ser a de eliminar as favelas, possibilitando a seus moradores a transferência para habitações populares condignas, construídas sob o patrocínio da Administração e acessíveis ao bolso das pessoas menos favorecidas. Ao contrário, entretanto, surge o legislador e dá à luz preceito como o do art.10 do Estatuto da Cidade, que, como dissemos, só irá servir para gerar um problema gravíssimo, que é o da perpetuação das favelas! Demagogia? Espírito tacanho incapaz de perceber a barbaridade cometida com tamanho disparate? Não sabemos!". SALLES, José Carlos de Moraes. Usucapião de bens móveis e imóveis. 6.ed. São Paulo: Revista dos Tribunais, 2005.p.319. 
conforme o art. $2^{\circ}$ da Lei $n^{\circ} 10.257 / 2001$, ao desenvolvimento das funções sociais da cidade e da propriedade urbana, em especial por meio de dois princípios:

II- gestão democrática por meio da participação da população e de associações representativas dos vários segmentos da comunidade na formulação, execução e acompanhamento de planos, programas e projetos de desenvolvimento urbano;

XIV - regularização fundiária e urbanização de áreas ocupadas por população de baixa renda mediante o estabelecimento de normas especiais de urbanização, uso e ocupação do solo e edificação, consideradas a situação sócio-econômica da população e as normas ambientais.

O diálogo das fontes traduz a idéia de influências recíprocas, de aplicação conjunta de duas normas ao mesmo tempo e ao mesmo caso, seja complementarmente, seja subsidiariamente. Seja permitindo a opção pela fonte prevalente ou mesmo permitindo uma opção por uma das leis em conflito abstrato, trata-se de uma solução flexível e aberta, de interpenetração, ou mesmo a solução mais favorável ao mais fraco da relação (tratamento diferente dos diferentes).

Este trabalho objetiva dar um passo inicial na utilização da técnica do diálogo das fontes para a verificação dos requisitos da usucapião coletiva, em especial o animus domini, de modo que a determinação do conteúdo da propriedade se vincule a centros de interesses extraproprietários $^{13}$, direcionando-se aquele direito a um máximo social ${ }^{14}$.

Para Gustavo Tepedino ${ }^{15}$,

(...) aquilo que na ordem liberal do Código Civil foi designado com a fórmula 'contradireito 'para expressar as situações dirigidas à realização da pessoa humana nos conflitos com o direito subjetivo, então símbolo do poder absoluto do proprietário, hoje, ao reverso, é de se considerar como situação jurídica constitucionalmente protegida( e neste sentido verdadeira e própria 'situação de vantagem'), entre os novos direitos da sociedade contemporânea. Representam, em uma palavra, não já uma reedição da exaltação do individualismo possessivo e da autonomia privada, mas um instrumento de promoção dos princípios do ordenamento.

13 Tais relações são descritas por Pietro Perlingieri em função dos aspectos estrutural e funcional da propriedade:" No perfil estrutural, a relação de propriedade é ligação(relazione) entre a situação do proprietário e aqueles que entram em conflito com esta e constituem centros de interesses antagônicos. A situação do proprietário é relevante somente enquanto pressupõe a obrigação de comportamento, de abstenção, às vezes a obrigação de cooperação dos outros sujeitos, que podem tornar-se, de fato, e concretamente, titulares da situação antagônica. O aspecto funcional é certamente prevalente na propriedade vista como relação; entre proprietário e terceiros, entre proprietário e vizinhos, entre proprietário e Estado, entre proprietário e entes públicos, existe relação - não de subordinação -, mas de coordenação. $O$ regulamento da propriedade às vezes dá prevalência ao interesse do proprietário, outras vezes àquele de outros sujeitos"(g.n.).PERLINGIERI, Pietro. Perfis do Direito Civil. Tradução de Maria Cristina de Cicco. Rio de Janeiro: Renovar, 1997.p.221-222.

14 TEPEDINO, Gustavo. Contornos constitucionais da propriedade privada. In: Temas de Direito Civil. Rio de Janeiro: Renovar, 1999.p.280-282. 


\section{2-Alcance da usucapião coletivo do artigo 10 do Estatuto da Cidade}

A situação do artigo 10 do Estatuto da Cidade não se limita à clássica situação de composse do Código Civil, que ocorre quando duas ou mais pessoas possuem em comum uma coisa, não se distinguindo qualquer porção de uso exclusivo dos compossuidores. A idéia do legislador, observa Francisco Eduardo Loureiro ${ }^{16}$, é a de alcançar aquelas situações em que pode haver posse materialmente certa, mas o seu objeto é fluido, as divisas movediças e, sobretudo, o perfil urbanístico, sob as lentes tradicionais do direito patrimonial privado, se mostra

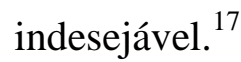

Ficam assim abrangidas as favelas, ou outros núcleos habitacionais semelhantes, não dotados de planejamento ou, por vezes, de serviços públicos essenciais, em que os moradores têm posse certa dos seus barracos, ou de pequenas casas de alvenaria, mas, "dado o caos urbanístico das vielas e a própria precariedade das construções, está a ocupação individual sujeita a constantes alterações qualitativas e quantitativas". ${ }^{18}$

\footnotetext{
$15 \quad$ Ibid., p.290.

16 LOUREIRO, op.cit., p.39.

17 Para Betânia Alfonsin, “A expressão 'onde não for possível identificar os terrenos ocupados por cada possuidor' deve ser lida de forma a abarcar a forma de ocupação de solo típica das favelas, em sua maioria desordenadas e densas. Em verdade, com a tecnologia existente hoje em dia, para fins de levantamento topográfico e cadastral, praticamente não há favelas onde não seja possível identificar os lotes. Assim, para que o dispositivo seja eficaz e atenda ao espírito da lei, será necessário flexionar o dispositivo para permitir que - em se tratando de favelas - possam ser estas regularizadas de forma coletiva". ALFONSIN, op.cit.,p.94. Em relação àquele requisito legal, merece ser transcrito trecho da sentença prolatada em ação de usucapião coletivo na região de Vila Manchete, Olinda, Pernambuco, pela Vara de Fazenda Pública daquela comarca, no processo $\mathrm{n}^{\circ}$ 2003.008384-4, publicada no Diário Oficial de 07.07.2005: “ Como sabemos, a popular Vila Manchete, verdadeiro aglomerado ao derredor da torre de transmissão da Rede Manchete de Televisão lá instalada, é constituída quase que absolutamente de construções disformes, irregulares e às vezes sobrepostas, servidas por estreitas ruelas e becos muito estreitos, que se entrelaçam em seus fugidios e sinuosos traçados, sendo extremamente difícil descrever-se em memorial o casebre e suas limitações e vinculá-lo ao seu possuidor, tudo a reclamar intervenção do poder público para que se dê aos seus moradores, todos de baixíssima renda, condições mais dignas de vivência, notadamente o remanejamento dos paupérrimos para residências novas e a disponibilização de creche e centro comunitário e desportivo, tudo sob o comando da sociedade condominial que se instalará e sob os auspícios do Banco Interamericano de Desenvolvimento. Os nomes das ruelas e a numeração das moradas - quase inúteis, pois não há serviços dos correios - foram escolhidos ao alvedrio dos ocupantes, sem ostentar nem mesmo uma ordenação lógica, embora haja fornecimento de energia elétrica e extensões de bicos de fornecimento de água, além de uma escola, no bairro vizinho, conhecida como 'Centro Embrião".
}

$18 \quad$ LOUREIRO, op.cit., p.39. 
A doutrina aponta outro dado importante, no sentido de que a lei especial pretendeu prestigiar os assentamentos informais de baixa renda, como opção política pela justiça social, não se estendendo a assentamentos informais na cidade cujos ocupantes são de classe média ou alta. ${ }^{19}$

A vedação de ser proprietário de outro imóvel urbano ou rural foi inserida no art. 10 da Lei n ${ }^{\circ}$ 10.257/01, consoante a orientação do artigo 183 da Constituição da República, para evitar a especulação imobiliária e favorecer aqueles que sonhem com o ideal da casa própria. ${ }^{20}$

É verdade que a adoção da usucapião para a regularização fundiária de favelas apresenta dificuldades, sublinhadas por Marco Aurélio Bezerra de $\mathrm{Mello}^{21}$ :

\begin{abstract}
No plano substancial, há que se reconhecer a existência de muitas favelas em que o direito à moradia é assegurado por intermédio da locação e (...) o locatário não ostenta o requisito subjetivo do animus domini, essencial para a convolação da posse prolongada no tempo em propriedade, além do que a Constituição estabelece como requisito para a inserção no programa de regularização fundiária urbana, por ela imaginado (usucapião especial urbano), não ser o morador titular de outro imóvel urbano ou rural. Essa lógica talvez mereça ser mantida, tendo em vista a diretiva constitucional e o que a inspirou que vem a ser o arrefecimento da nociva especulação imobiliária em assentamentos humanos protagonizados por pessoas de baixa renda.
\end{abstract}

19 GOMES, op.cit., p.728. O requisito da baixa renda, para a autora, deve ser analisado conforme a receita e as despesas da família:’Tal prática é uma interpretação por analogia, diante do silêncio do Estatuto da Cidade, da prática adotada nos alimentos, conforme o equilíbrio do binômio necessidade/possibilidade do art. $1694, \S 1^{\circ}$ do Código Civil de 2002, bem como o disposto no art. $1^{\circ}, \S 3^{\circ}$ da Lei ${ }^{\circ}{ }^{\circ} 5478 / 68$, assim, a alegação de baixa renda será admitida com presunção de veracidade, salvo em hipótese de provas em contrário trazidas em contestação".

20 Ibid., p.736. Escreve a autora: "É certo que, quando há um projeto urbanístico que noticie a regularização fundiária, verifica-se um fluxo crescente de ocupação da área beneficiada, desfigurando a natureza da posse inicial. Observe-se que a figura do especulador imobiliário existe na favela, e em todos os espaços de exclusão social a semelhança da sua existência como um outro espaço urbano qualquer.

Portanto, a intenção do legislador especial, nas pegadas do legislador constitucional, foi descaracterizar essa prática abusiva, permitindo que aqueles que, verdadeiramente, necessitem de um teto e possuam o direito pleiteado, sejam agraciados com a medida judicial, conferindo-lhes a usucapião".

21 Legitimação da posse dos imóveis urbanos e o direito de moradia. Rio de Janeiro: Lumen Juris, 2008. p.137. Para o mesmo autor, "se o rito da ação de usucapião fora criado no âmbito de uma visão individual de proteção dos interesses, isso acaba se refletindo na dificuldade de adequação dessa moldura dentro do contexto de uma favela. Talvez por isso nas ações de usucapião não se possam dispensar a citação pessoal de todos os confinantes, por edital de eventuais interessados(sic); a oitiva das Fazendas Federal, Estadual e Municipal, além do Ministério Público e de plantas que tragam a precisa identificação do imóvel. Neste último caso, em se tratando de favela, se a norma for aplicada com rigor, isso se projetaria na necessidade de confecção de plantas da área maior, de sobreposição sobre esta e a citação pessoal dos confinantes internos(outros possuidores) e externos". A mesma preocupação é partilhada por Edésio Fernandes: “(...)a caracterização do direito de usucapião tradicional é extremamente difícil, porque os códigos dão aos proprietários de terras um leque de instrumentos legais com os quais questionar, em juízo, a ocupação da terra. Assim, conseqüentemente, as invasões deixam de ser 'pacíficas'. No caso das favelas, sua aplicação é quase impossível,porque a dinâmica, alta mobilidade e natureza coletiva do fenômeno da favelização não se enquadram nos requerimentos técnicos e individualistas da legislação civil. Além disso, o direito de usucapião não pode ser aplicado de maneira alguma aos casos de invasões de terras públicas. Dessa forma, não pode ser reivindicado por cerca de $50 \%$ dos favelados, aqueles que ocupam terras públicas nas várias cidades 


\section{3-Diálogo das fontes entre o Estatuto da Cidade e o Código de Defesa do Consumidor}

Como ensina Stefano $\operatorname{Rodotà~}^{22}$, a plenitude da cidadania coincide com a assunção total da condição de consumidor, reportando-se o fenômeno do consumo, na experiência comunitária européia, não somente a índices e critérios de tipo econômico, mas sim aos direitos fundamentais e garantias integrais em prol da pessoa.

A defesa do consumidor, consagrada nos artigos $5^{\circ}$, XXXII e 170, V, ambos da Constituição da República, deve ser coligada à cláusula geral de tutela da personalidade, a partir

do princípio da dignidade da pessoa humana (art. $1^{\circ}$, III), considerado ainda o objetivo da República no sentido da erradicação da pobreza e marginalização, reduzindo-se as desigualdades sociais e regionais (art. $3^{\circ}$, III).

Trata-se, para Eros Roberto Grau ${ }^{23}$, de

(...) princípio constitucional impositivo (Canotilho) a cumprir dupla função, como instrumento para a realização do fim de assegurar a todos existência digna e objetivo particular a ser alcançado. No último sentido, assume a função de diretriz (Dworkin) norma-objetivo - dotada de caráter constitucional conformador, justificando a reivindicação pela realização de políticas públicas.

O sistema de amparo às relações de consumo surge, portanto, em consonância com a axiologia e principiologia constitucional, com o objetivo de conferir concretude ao princípio da igualdade material, de modo que os direitos básicos dos consumidores são normas materialmente constitucionais (em que pese não se situarem topograficamente no texto constitucional) fundamentais, dotados de eficácia horizontal, irradiando-se por todo o ordenamento jurídico, público e privado. ${ }^{24}$

Referindo-se especificamente ao diálogo entre o Código Civil e o Código de Defesa do Consumidor - situação essa que pode ser estendida ao Estatuto da Cidade, haja vista o fundamento constitucional que permeia ambos os diplomas -, Claudia Lima Marques contempla,

brasileiras".FERNANDES, Edésio. Perspectivas para a renovação das políticas de legalização de favelas no Brasil. In: Regularização fundiária plena; referências conceituais. Brasília: Ministério das Cidades, 2007.p.39.

22 Persona-consumatore. In: STANZIONE, Pasquale. La tutela del consumatore tra liberismo e solidarismo. Napoli: Edizioni Scientifiche Italiane, 1999. p.20(tradução livre).

23 A ordem econômica na Constituição de 1988. 8 ed.. São Paulo: Malheiros, 2003.p.216.

24 FACHIN, Luiz Edson. As relações jurídicas entre o novo Código Civil e o Código de Defesa do Consumidor: elementos para uma teoria crítica do direito do consumidor. In: CAPAVERDE, Aldaci do Carmo; CONRADO, Marcelo. Repensando o direito do consumidor; 15 anos do CDC. Curitiba:OAB-PR, 2005. p.46-48. 
enquanto formas de manifestação, aplicação simultânea, coordenada e influências recíprocas sistemáticas entre aquelas leis: ${ }^{25}$

1-Aplicação simultânea das duas leis: uma pode servir de base conceitual para a outra (diálogo sistemático de coerência), especialmente se uma lei é geral e a outra especial; se uma é lei central do sistema e a outra uma microssistema específico, não completo materialmente, apenas com completude subjetiva de tutela de um grupo da sociedade.

2-Aplicação coordenada das duas leis: uma pode complementar a aplicação da outra, a depender de seu campo de aplicação no caso concreto (diálogo sistemático de complementaridade e subsidiariedade em antinomias aparentes ou reais), a indicar a aplicação complementar tanto de suas normas, quanto de seus princípios, no que couber no que for necessário ou subsidiariamente;

3-Influências recíprocas sistemáticas: no caso de uma possível redefinição no campo de aplicação de uma lei (assim, por exemplo, as definições de consumidor stricto sensu e consumidor equiparado, que podem sofrer as influências finalísticas do Código Civil, uma vez que esta lei nova vem justamente para regular as relações entre iguais, dois iguais-consumidores ou dois iguais-fornecedores entre si, e no caso de dois fornecedores trata-se de relações empresariais típicas, em que o destinatário final fático da coisa ou do fazer comercial é outro empresário comerciante. É a influência do sistema especial no geral e do geral no especial, um diálogo de double sens (diálogo de coordenação e adaptação sistemática).

O diálogo entre o Código do Consumidor e o Estatuto da Cidade compreende sobretudo a segunda e a terceira modalidades acima, ou seja, a aplicação coordenada e as influências recíprocas sistemáticas.

A gestão democrática da cidade, contemplada nos artigos $2^{\circ}$, II e 43 da Lei $n^{\circ} 10.257 / 01$, encontra paralelo na redação do art. $6^{\circ}$, IX do Código de Defesa do Consumidor, vetado pelo Presidente da República ${ }^{26}$, que previa como direito básico do consumidor "a participação e consulta na formulação das políticas que os afetem diretamente, e a representação de seus interesses por intermédio das entidades públicas ou privadas de defesa do consumidor".

\footnotetext{
$25 \quad$ Diálogos...op.cit, p.91

26 O aludido veto se baseou nas seguintes razões: "o dispositivo contraria o princípio da democracia representativa ao assegurar, de forma ampla, o direito de participação na formulação das políticas que afetam diretamente o consumidor. O exercício do poder pelo povo faz-se por intermédio de representantes legalmente eleitos, excetuadas as situações previstas expressamente na Constituição - art. 14, I. Acentue-se que o próprio exercício da soberania popular no processo legislativo está sujeito a condições estatais - art. $61, \S 2^{\circ}, \mathrm{CR}$ ”. O veto foi profundamente criticado pela doutrina, sendo que, para José Geraldo Brito Filomeno, "não se pretendeu conferir a organizações de consumidores a prerrogativa legiferante, ou de simples iniciativa do processo legislativo. O objetivo era apenas dar-lhes oportunidade de serem ouvidas, sempre que estivessem em discussão projetos de lei que digam respeito aos interesses dos consumidores". FILOMENO, José Geraldo Brito. Código Brasileiro de Defesa do Consumidor: comentado pelos autores do anteprojeto. 5.ed. Rio de Janeiro: Forense Universitária, 1997.p.120.
} 
Trata-se, em outras palavras, do direito do consumidor a ser ouvido, na medida dos seus interesses, assim como a gestão democrática da cidade "implica a participação dos seus cidadãos e habitantes nas funções de direção, planejamento, controle e avaliação das políticas urbanas". ${ }^{27}$

Os princípios da dignidade da pessoa humana, da solidariedade social e da erradicação da pobreza e marginalização, com a redução das desigualdades sociais e regionais, servem de fundamento constitucional a ambos os diplomas legais, cada qual, porém, dirigido à regulação das situações jurídicas que lhe são específicas.

Outro exemplo de aplicação coordenada entre ambas as leis pode ser extraído do art. $4^{\circ}$, caput do Código de Defesa do Consumidor, que prevê os objetivos da Política Nacional das Relações de Consumo:

Art. $4^{\circ}$ A Política Nacional das Relações de Consumo tem por objetivo o atendimento das necessidades dos consumidores, o respeito à sua dignidade, saúde e segurança, a proteção dos interesses econômicos, a melhoria da sua qualidade de vida, bem como a transparência e harmonia das relações de consumo (g.n.)

Há, portanto, notáveis pontos de convergência entre ambos os estatutos, podendo ser as idéias de dignidade e melhoria da qualidade de vida diretamente associadas ao direito de moradia, inscrito no art. $6^{\circ}$ da Constituição da República, como direito social, nas palavras de José dos Santos Carvalho Filho ${ }^{28}$ :

(...) são realmente indissociáveis a vida digna e a moradia (...). Não custa lembrar, neste passo, que o usucapião especial urbano e a concessão urbanística de uso especial demandam, como um dos requisitos da regularização fundiária, o uso do imóvel para moradia do interessado ou de sua família. A regularização, desse modo, alcança direito fundamental - o de moradia - e, conseqüentemente, retrata também um direito, indiscutivelmente de natureza fundamental.

Todos esses elementos são acima invocados para conduzir à conclusão de que ter direito à regularização fundiária é ter um direito fundamental, tantos são os princípios e outros direitos fundamentais a que é indissoluvelmente atrelado.

O diálogo de coordenação e aplicação sistemática permite a transposição da reflexão doutrinária e jurisprudencial da praxis do direito do consumidor, durante o período de vigência do $\mathrm{CDC}^{29}$, no que for compatível, como critério para a fixação dos moradores da favela ao solo urbano. Essa técnica de coordenação das diferentes fontes jurídicas pode contribuir, juntamente

27 BUCCI, Maria Paula Dallari. Gestão democrática da cidade. In:DALLARI, Adilson Abreu; FERRAZ, Sergio(coord.)Estatuto da Cidade. São Paulo: Malheiros, 2003.p.323.

28 Regularização fundiária: direito fundamental na política urbana. Revista de Direito Administrativo. Rio de

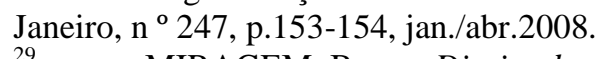

29 MIRAGEM, Bruno. Direito do consumidor. São Paulo: Revista dos Tribunais, 2008.p.53-54. 
com os demais requisitos legais, como o tempo, o animus domini e a continuidade de forma mansa e pacífica da posse, para a promoção da usucapião coletivo do Estatuto da Cidade.

Da mesma forma, o princípio da vulnerabilidade, guia da aplicação do Código de Defesa do Consumidor (art. $\left.4^{\circ}, \mathrm{I}\right)$, pode influenciar uma redefinição do âmbito de aplicação da usucapião coletivo, com vistas à proteção do consumidor-possuidor nas comunidades da baixa renda.

A vulnerabilidade pode ser extraída, dentre outros fatores, da constatação de que a opção pela habitação em espaços de exclusão social, nas palavras de Rosângela Gomes ${ }^{30}$, não ocorre por uma escolha pessoal, mas simplesmente pela sua ausência:

Quer dizer, estas pessoas não têm alternativa diante da necessidade de proximidade com a oferta de emprego, escola, hospital, serviços em geral que barateiam o custo de vida e permitem uma economia em transporte que é direcionada para outras despesas essenciais tais como: comida, remédios, moradia (aluguel, taxas etc.).

\title{
Certos fatores políticos podem ser igualmente apontados como causa desse processo de
} exclusão, a justificar a vulnerabilidade dos moradores das favelas, como bem sublinha Edésio Fernandes $^{31}$ :

\begin{abstract}
Os assentamentos informais - e a conseqüente falta de segurança da posse, vulnerabilidade política e baixa qualidade de vida dos seus ocupantes que lhes são características - resultam não somente do padrão excludente dos processos de desenvolvimento, planejamento e gestão das áreas urbanas, mas também da natureza da ordem jurídica em vigor. Ao longo do processo de urbanização intensiva, mercados de terras especulativos, sistemas políticos clientelistas e regimes jurídicos elitistas não têm oferecido condições suficientes, adequadas e acessíveis à terra urbana e à moradia, para os grupos sociais mais pobres, assim provocando a ocupação irregular e inadequada do meio ambiente urbano.
\end{abstract}

\footnotetext{
$30 \quad$ Op.cit.,p.728

31 Regularização de assentamentos informais : o grande desafio dos municípios, da sociedade e dos juristas brasileiros. In: Regularização fundiária plena; referêcias conceituais. Brasília: Ministério das Cidades, $2007 . p .20$. Prossegue o autor: “(...)deve-se ressaltar a dificuldade de implementação das leis em vigor, devida em parte à falta de informação e educação jurídicas, à limitada capacidade de ação das agências públicas, bem como às difíceis e limitadas condições de acesso ao poder judiciário para a promoção do reconhecimento dos interesses sociais e ambientais.

A combinação entre esses processos tem feito com que o lugar dos pobres nas cidades seja as áreas periféricas, ou mesmo as áreas centrais não dotadas de infra-estrutura urbanística adequada e, cada vez mais, áreas não adequadas à ocupação humana e de preservação ambiental(...)Deve-se ressaltar que, ainda que por todas essas razões a ocupação informal tenha se tornado a única opção de moradia permitida aos pobres nas cidades, não se trata certamente de uma boa opção - em termos urbanísticos, sociais e ambientais - e nem, ao contrário do que muitos pensam, de uma opção barata, já que o crescimento das práticas de informalidade e o adensamento das áreas já ocupadas têm gerado custos muito elevados dos terrenos e aluguéis ali localizados. Em outras palavras, os pobres do Brasil pagam um preço cada vez mais alto - em muitos sentidos - para viverem em condições precárias, indignas e inaceitáveis".
} 
Ambos os diplomas, Estatuto da Cidade e Código de Defesa do Consumidor, são leis de função social, intervindo de maneira imperativa em relações jurídicas de direito privado, antes dominadas pela idéia de autonomia da vontade, caracterizando-se por ${ }^{32}$

(...) impor as novas opções valorativas que devem orientar a sociedade, e por isso optam, geralmente, em positivar uma série de direitos assegurados ao grupo tutelado e impõem uma série de novos deveres imputados a outros agentes da sociedade, os quais, por sua profissão ou pelas benesses que recebem, considera o legislador que possam e devam suportar estes riscos. São leis, portanto, que nascem com a árdua tarefa de transformar uma realidade social, de conduzir a sociedade a um novo patamar de harmonia e respeito nas relações jurídicas. Para que possam cumprir sua função, o legislador costuma conceder a essas novas leis um abrangente e interdisciplinar campo de aplicação, assim como impor uma lista de direitos básicos ao sujeito tutelado.

\section{4-O consumo nas favelas como critério para a verificação da posse ad usucapionem}

No Município do Rio de Janeiro, o programa Favela Bairro, implementado a partir de 1993, destaca-se como a iniciativa de maior amplitude implementada ao longo da história das favelas cariocas, tendo por objetivo integrar tais comunidades à cidade, com toda a infraestrutura, serviços públicos e privados, equipamentos públicos e políticas sociais. ${ }^{33}$

Dentre outras medidas urbanísticas, o Favela Bairro permite que os moradores tenham acesso ao crédito para compra de material de construção, por intermédio da Caixa Econômica Federal, além de cursos de informática, à legalização de estabelecimentos comerciais e à instalação de serviços telefônicos. ${ }^{34}$

A imprensa tem noticiado a existência dos mais variados serviços, como lan houses, cursos de inglês alternativos, a preços menores do que os convencionais, lojas instaladas por operadoras de telefonia celular e até empresas de factoring. ${ }^{35}$

32 MARQUES, A Lei 8078/90 e os Direitos Básicos do Consumidor.In: BENJAMIN;MARQUES;BESSA, op.cit., p.55.

POGREBINSCHI, op.cit, p.249 e 251. Na indagação da autora: "De que adianta atingir 158 comunidades diferentes, quando em apenas uma delas se conseguiu completar o processo previsto e prometido? De que adianta gerar tanta infra-estrutura e serviços, quando os moradores permanecem sem um de seus direitos civis básicos, à propriedade? De que adianta tentar prover o acesso a bens econômicos e culturais, quando a ausência de um título de propriedade pode muitas vezes impedir o desfrute desses bens? De que adianta, por exemplo, garantir acesso ao crédito, quando este está condicionado à apresentação de um título de propriedade? “.

$34 \quad$ Idem

35 FAVELA S/A . No mercado de favelas, há desde negócios mais sofisticados, como telefonia, à factoring que encobre agiotagem. $O$ Globo Online. Rio de Janeiro, 23 ago. 2008. Disponível em : <http://oglobo.globo.com/rio/mat/2008/08/23> Acesso em: 26 nov. 2008. 
A Revista Época, em reportagem intitulada Consumo sobe às favelas, divulgou os seguintes dados, oriundos de pesquisa do Instituto Superior de Estudos da Religião (ISER), intitulada Favela, Opinião e Mercado ${ }^{36}$ :

Nas favelas do Rio de Janeiro os moradores tornaram-se consumidores mais rapidamente do que no Estado do Rio e no País. Um levantamento socioeconômico feito pelo instituto de pesquisa Favela, Opinião e Mercado, do Instituto Superior de Estudos da Religião (Iser), mostrou que apenas $0,9 \%$ dos moradores de favela estão em situação de miséria (fora das classes de consumo), enquanto na Região Metropolitana o número é de $2 \%$ dos habitantes e no país é $4 \%$. Na favela há mais pessoas na classe média e menos na classe alta do que na média das regiões metropolitanas do país e do Rio(...)

Isoladamente, o resultado do levantamento de bens poderia mostrar até que a favela é mais rica do que a cidade. Comparando o levantamento feito pelo Iser e os dados do Censo 2000 do IBGE, há mais moradores nas favelas que têm geladeira, máquina de lavar, TV e videocassete do que no resto do país e no Rio. Entre os bens mais importantes, na favela só há menos carros. O perfil consumidor da favela impressionou Paulo Castro, diretor da criação da agência $V$ \& $S$, que vai produzir uma campanha publicitária para divulgar o levantamento do Iser:

- As grandes empresas iam para as favelas num vôo cego. Esse tipo de pesquisa, que nunca foi feita porque havia preconceito, abre uma porta para novos negócios (...)

Como a favela conseguiu mais rapidamente transformar seus moradores em consumidores do que a média do estado e do país e, principalmente, onde estão os verdadeiros pobres da Região Metropolitana são indagações que não encontram mais resposta no senso comum, que continua a enxergar as favelas como o único reduto de pobreza da cidade.

O direito básico do consumidor à liberdade de escolha nem sempre é observado nas favelas, o que justifica o reconhecimento do princípio da vulnerabilidade nas relações de consumo ali realizadas como um critério para a verificação da posse ad usucapionem, no tocante à fixação dos possuidores ao solo ${ }^{37}$ :

A venda de drogas, que sempre foi um dos negócios mais rentáveis nas favelas do Rio, vem perdendo espaço para serviços que também envolvem cifras milionárias: o pedágio cobrado de vans, a exploração ilegal de TV a cabo e o ágio sobre o comércio de gás. $\mathrm{O}$ faturamento dessas atividades, controladas por milicianos ou traficantes, é de cerca de $\mathrm{R}$ \$ 280 milhões por ano, segundo estimativas de sindicatos dos setores e da polícia. Isso sem contar os rendimentos do controle de pontos de moto táxis e do acesso à Internet (...)

Se no asfalto o consumidor pode escolher a mercadoria mais barata ou a que mais the agrada, nas favelas as regras são bem diferentes. Muitas vezes sem liberdade de

$36 \quad$ Disponível em: <http://revistaepoca.globo.com/Revista/Epoca/0,,EDG51026-6012,00CONSUMO+SOBE> Acesso em : 27 nov.2008.

37 PONTES, Fernanda. Os mercadores da desilusão. Jornal $O$ Globo. Rio de Janeiro, p.17, 27 ago. 2008:"Segundo estimativas da polícia, cerca de 70\% dos 570 mil domicílios de favelas pagam por TV a cabo clandestina. A mensalidade custa de R \$ 20 a R \$ 35 e o preço da instalação varia de $\mathrm{R} \$ 45$ a $\mathrm{R} \$ 50$. O funcionamento das centrais clandestinas, incluindo a cobrança das tarifas, demanda um pequeno grupo de pessoas, entre moradores e técnicos(...)Quem paga pelo 'gatonet' dificilmente tem idéia de que está, indiretamente, financiando o crime. A distribuição de TV por assinatura é feita de forma tão natural que o vencimento da fatura é anunciado nos altofalantes da rádio comunitária da Favela de Ramos, no Complexo da Maré 'Não esqueçam de pagar a net', avisam os locutores". 
escolha, moradores são obrigados a comprar produtos de primeira necessidade, como é o caso do botijão de gás, em locais específicos, mesmo pagando mais caro por isso (g.n.).

A regularização fundiária, tendo por objetivo a integração socioespacial dos ditos assentamentos informais, deve igualmente permitir a revisão desse perverso pacto social, sobretudo nas áreas controladas pelo tráfico de drogas e pelo crime organizado. Lado a lado com o reconhecimento do animus domini e da posse mansa, ininterrupta e pacífica, "é preciso ampliar o acesso ao mercado formal a uma parcela mais ampla da sociedade, sobretudo os grupos de renda média-baixa". 38

O consumo é uma das maneiras de realização da função social da posse, que, além do trabalho realizado sobre a terra, compreende um aspecto econômico, destacando-se, na teoria de Saleilles, a importância do acesso dos homens ao uso dos bens, de maneira tão arraigada às necessidades humanas. ${ }^{39}$

O corpus, para Saleilles, consiste na exteriorização da utilização econômica da coisa, conceituando-se como o conjunto de fatos que revelam uma relação de exploração da coisa a serviço do indivíduo, o que decorre da observação dos fatos sociais. ${ }^{40}$ Porém, ao lado da apreensão física da coisa e da vontade, a utilização econômica alia-se a outro elemento externo,

38 FERNANDES, Regularização..., op.cit., p.24. O autor, op.cit, p.48-50, comenta o argumento utilitarista do economista peruano Hernando de Soto, que dá uma dimensão econômica ao problema: "ele propõe que negócios, atividades e assentamentos ilegais sejam vistos não como 'problema', mas como 'capital morto'de valor inestimável, o qual, se devidamente reanimado e transformado em 'capital líquido', pode vir a reativar sobremaneira a economia urbana e a combater a crescente pobreza social(...)Hernando de Soto sugere que, para terem acesso a crédito e investirem nos seus negócios e casas, os moradores de assentamentos ilegais têm de se sentirem seguros da sua posse, o que só poderia se dar pela legalização de suas formas precárias de ocupação. Em outras palavras, trata-se de legalizar o ilegal.(...)Como resultado, ao invés de questionar a natureza da ordem jurídica que gera a ilegalidade urbana, a legalização plena ( e sem maiores qualificações) de negócios informais e o reconhecimento de títulos individuais de propriedade plena para os moradores em assentamentos urbanos informais - são propostos em diversos países como a maneira 'radical' de transformar a economia urbana e assim 'resolver o problema'da pobreza urbana". Dentre as maiores críticas ao pensamento do economista peruano, merecem ser destacadas a função especulativa da propriedade imobiliária na América Latina, dificultando o acesso de grande parte da população à terra urbana e moradia, e, sobretudo, o fato de suas idéias não reconhecerem que, em assentamentos consolidados, os habitantes das favelas já acumularam recursos e adquiriram bens, o que tem sido possível em parte pelo seu acesso ao crédito, ainda que não por instituições formais.

39 La posesión. Tradução J.M.Navarro de Palencia. Madrid: Libraria General de Victoriano Suárez, 1909.p.159-160. Outra referência às necessidades humanas pode ser encontrada na obra de Rudolf Von Ihering, em cujo ensinamento "a posse não constitui um fim em si mesma, senão um meio para um fim; constitui a condição de fato em virtude da qual são possíveis os três modos de usar a coisa, utilizando-a para as necessidades humanas e compreendendo, por tanto, todo o conteúdo substancial da propridade(...)A posse jamais pode ser fim em si mesma, não tem como tal qualquer valor econômico, e somente adquire este quando permite realizar outra coisa que tem um valor econômico também". VON IHERING, Rudolf. La posesión. Tradução Adolfo Posada. 2.ed. Madrid: Editorial Reus, 1926.p.283.

$40 \quad$ ALVES, José Carlos Moreira. Posse. v.1. Rio de Janeiro: Forense, 1999.p.236-237. 
qual seja, a consciência social, tendo em vista o organismo ou comunidade a que pertence o possuidor. $^{41}$

Justifica-se a relevância da posse enquanto condição ou meio de utilização econômica da coisa, devendo ser evitado um formalismo ${ }^{42}$ exacerbado na sua prova em juízo; a existência de relações de fornecimento de produtos e serviços pode ser considerada pelo julgador como regra de experiência comum, subministrada pela observação do que ordinariamente acontece (Código de Processo Civil, art.335), em especial quanto à verificação do animus domini.

Isso pode ser mais facilmente visualizado nos produtos e serviços contratados em função das necessidades de moradia, como gás, energia elétrica, telefonia e televisão a cabo, dentre outros, traduzindo de maneira mais explícita a fixação do possuidor ao imóvel.

A função social assume, na lição de Pietro Perlingieri ${ }^{43}$, um papel de tipo promocional,

no sentido de que a disciplina das formas de propriedade e as suas interpretações deveriam ser atuadas para garantir e promover os valores sobre os quais se funda o ordenamento. E isso não se realiza somente finalizando a disciplina dos limites à função social. Esta deve ser entendida não como uma intervenção "em ódio" à propriedade privada, mas torna-se "a própria razão pela qual o direito de propriedade foi atribuído a um determinado sujeito", um critério de ação para o legislador, e um critério de individuação da normativa a ser aplicada para o intérprete chamado a avaliar as situações conexas à realização dos atos e de atividades do titular.

A jurisprudência é ainda tímida no reconhecimento do direito à moradia digna por parte dos habitantes das favelas, embora algumas manifestações isoladas dos Tribunais venham contribuindo para a concretização dos princípios constitucionais que regulam a matéria.

$41 \quad$ Op.cit.,p.396-397: "Não basta para a relação possessória nem o simples contato corporal com a coisa, nem o título jurídico em que este se funda; a relação possessória é um todo complexo que encerra ambos os elementos como fatores reais da situação econômica e social daquele que a exerce; e é esta a situação que o direito protege antes de que se estatua sua legitimidade jurídica, porque todo aquele que aqui na terra a usa em paz e como dono dos bens deste mundo, preenche uma função útil em si, boa para si e boa também para o organismo social a que pertence. A comunidade deve defendê-lo e assegurar-lhe o triunfo contra todo agressor que não prove um direito superior ao $\operatorname{seu}(. .$.$) "'(g.n.).$

${ }_{42}$ É de se lamentar a posição adotada pela Juíza de Direito da Comarca de Pinhais-Paraná, no julgamento de ação de usucapião coletivo envolvendo a área da Vila União, processo ${ }^{\circ} 1517 / 2002$, tendo a sentença, prolatada em 08.09.03, extinto o processo sem resolução do mérito, por carência de ação, na forma a seguir transcrita: "Trata-se de ação de usucapião, onde os autores pretendem adquirir o domínio do imóvel objeto da ação, por meio de prescrição aquisitiva, ao argumento de que possuem os bens de forma mansa e pacifica, conforme consignado na petição inicial.Na espécie, o presente pedido não pode ser acolhido. A parte autora, acostando documentos dos ocupantes dos lotes descritos na exordial, juntaram contratos particulares de compra e venda, sendo que nestes contratos figuram como 'vendedores' terceiras pessoas as quais alegam que cedem e transferem todos os seus direi tos de posse e usufruto, mencionando o metragem do lote.Verificando a documentação acostada aos autos, pelo contestante restou demonstrado que os imóveis sobre os quais pretende-se usucapir, foram objeto de ação de reintegração de posse, sendo certa a propriedade dos requeridos". Tal sentença foi reformada em virtude de acordo judicial para a regularização fundiária da área, sendo ressalvado o prosseguimento da ação de reintegração de posse em face dos adquirentes que não aderiram àquele termo. 
Embora negando a aquisição por usucapião como matéria de defesa, em ação reivindicatória referente a lotes de terreno ocupados por favela, a $8^{\mathrm{a}}$ Câmara Cível do Tribunal de Justiça do Estado de São Paulo igualmente negou o direito de seqüela dos proprietários, por entender que o abandono dos imóveis, que passaram a constituir uma comunidade habitada por pessoas de baixa renda, constitui exercício anti-social do direito de propriedade que não pode persistir no atual sistema constitucional. ${ }^{44}$

Um dos principais fatores levados em consideração pelo mencionado acórdão foi a existência de equipamentos urbanos, além de comércio e serviços, constituindo realidade social que não pode ser esquecida pelo direito (TJ-SP, $8^{\mathrm{a}} \mathrm{CC}$, ap.civel 212.726-1-8, Rel.Des.José Osório, j.16.12.1994):

Trata-se de favela consolidada, com ocupação iniciada há cerca de 20(vinte) anos. Está dotada, pelo Poder Público, de pelo menos 03(três) equipamentos urbanos: água, iluminação pública e luz domiciliar. As fotos de fls. 10/13 mostram algumas obras de alvenaria, os postes de iluminação, um pobre ateliê de costureira etc., tudo a revelar uma vida urbana estável, no seu desconforto.

O objeto da Ação Reivindicatória é, como se sabe, uma coisa corpórea, existente e bem definida. Veja-se, por todos, Lacerda de Almeida:

"Coisas corpóreas em sua individualidade, móveis ou imóveis, no todo ou em uma quota-parte, o instituem o objeto mais freqüente do domínio, e é no caráter de concretas que podem ser reivindicadas (...)"(...)

No caso dos autos, a coisa reivindicada não é concreta, nem mesmo existente. É uma ficção.

Os lotes de terreno reivindicados e o próprio loteamento não passam, há muito tempo, de mera abstração jurídica. A realidade urbana é outra. A FAVELA JÁ TEM VIDA PRÓPRIA, ESTÁ, REPITA-SE, DOTADA DE EQUIPAMENTOS URBANOS. Lá vivem muitas centenas, ou milhares, de pessoas. Só nos locais onde existiam 09(nove) lotes reivindicados residem 30(trinta) famílias. Lá existe uma outra realidade urbana, com vida própria, com os direitos civis sendo exercitados com naturalidade. O comércio está presente, serviços são prestados, barracos são vendidos, comprados, alugados, tudo a mostrar que o primitivo loteamento hoje só tem vida no papel.

A realidade concreta prepondera sobre a "pseudo-realidade jurídica-cartorária". Esta não pode subsistir, em razão da perda do objeto do direito de propriedade. Se um cataclismo, se uma erosão física, provocada pela natureza, pelo homem ou por ambos, faz perecer o imóvel, perde-se o direito de propriedade.

O desalojamento forçado de 30(trinta) famílias, cerca de 100(cem) pessoas, todas inseridas na comunidade urbana muito maior da extensa favela, já consolidada, implica uma operação cirúrgica de natureza ético-social, sem anestesia, inteiramente incompatível com a vida e a natureza do Direito (g.n.).

\section{5-Conclusão}


A partir da técnica do diálogo das fontes entre o Estatuto da Cidade e o Código de Defesa do Consumidor, ambos centrados na promoção da pessoa humana, em especial a partir da vulnerabilidade desta, pode ser mais bem operacionalizado o instituto da usucapião coletivo introduzido pelo artigo 10 da Lei n o. 10.257/01.

A aplicação coordenada e as influências recíprocas sistemáticas entre ambos os diplomas podem ser visualizadas a partir das relações de consumo realizadas nos assentamentos informais (favelas), envolvendo os mais variados produtos e serviços.

Logo, a existência de relações de consumo deve ser admitida como um dos critérios para a aferição da prova da fixação dos possuidores no solo, podendo ser verificada pelo julgador como regra de experiência comum, subministrada pela observação do que ordinariamente acontece (Código de Processo Civil, art.335).

Para tal fim, o consumo atua como uma das manifestações da função social da posse, mesmo que em confronto com uma situação proprietária, o que pode ser mais facilmente visualizado nos produtos e serviços contratados em função das necessidades de moradia, como gás, energia elétrica, telefonia e televisão a cabo, dentre outros, traduzindo de maneira mais explícita a fixação do possuidor ao imóvel.

Os programas de regularização fundiária, por meio de institutos como a usucapião coletiva, devem contribuir para a inclusão dos moradores das favelas na ordem políticoeconômica da cidade, o que pressupõe igualmente o reconhecimento da aquisição de bens e serviços, a título oneroso, como uma situação sujeita à ordem jurídica, e não à margem desta.

Mais do que atender a argumentos econômicos ou utilitaristas ou às regras de mercado, o objetivo é concretizar as normas constitucionais relativas ao direito de moradia, enquanto instrumento indispensável à formação da cidadania, salvaguardando a dignidade da pessoa humana (art. $1^{\text {o }}$, III, Constituição da República) e a erradicação da pobreza e marginalização, além da redução das desigualdades sociais (art. $3^{\circ}$, III, Constituição da República).

Aqueles valores fundamentais do sistema servem de guia a ambos os diplomas legais, seja na regulação das situações jurídicas que lhe são específicas a cada qual, ou, como ora se sustenta, sobretudo na complementação entre ambos, cujos campos de atuação podem ser inclusive redefinidos. 


\section{6-Bibliografia}

ALBUQUERQUE, Ana Rita Vieira. Da função social da posse. 2. ed. Rio de Janeiro: Lumen Juris, 2002.

ALFONSIN, Betânia. O significado do Estatuto da Cidade para os processos de regularização fundiária no Brasil. In: Regularização fundiária plena; referências conceituais. Brasília: Ministério das Cidades, 2007.

ALMEIDA, Francisco de Paula Lacerda de. Direito das cousas. Rio de Janeiro: J. Ribeiro, 1908.

ALVES, José Carlos Moreira. Posse. v.I. Rio de Janeiro: Forense, 1999.

BARASSI, Lodovico. Proprietà e comproprietà. Milano: Giuffrè, 1951.

BUCCI, Maria Paula Dallari. Gestão democrática da cidade. In: DALLARI, Adilson Abreu;

FERRAZ, Sergio (coord.) Estatuto da Cidade; comentários à Lei Federal 10.257/2001 São Paulo: Malheiros, 2003

CALDAS, Roberto Correia da Silva Gomes. O fenômeno da legalização das favelas e sua transmutação em concessões públicas. Interesse Publico, Porto Alegre, v. 8, n.37, p. 321-334, maio/jun. 2006.

CARVALHO FILHO, José dos Santos. Regularização fundiária: direito fundamental na política urbana. Revista de Direito Administrativo. Rio de Janeiro, v.247, p.139-155, jan./abr.2008.

CONSUMO sobe as favelas. Revista Época. Rio de Janeiro, ed.523, 26 mai.2008. Disponível em: <http://revistaepoca.globo.com/Revista/Epoca/0, EDG51026-6012,00-CONSUMO+SOBE> Acesso em: 27 nov.2008

DALLARI, Dalmo de Abreu. Usucapião coletiva. Revista de Informação Legislativa. Brasília, $\mathrm{n}^{\circ}$ 115, p.373-380, jul./set.1992

DOMANSKI, Marcelo. Posse; da segurança jurídica à questão social. Rio de Janeiro: Renovar, 1998.

ESPÍNOLA, Eduardo. Posse, propriedade, compropriedade ou condomínio, direitos autorais. Rio de Janeiro: Conquista, 1956.

FACHIN, Luiz Edson. As relações jurídicas entre o novo Código Civil e o Código de Defesa do Consumidor: elementos para uma teoria crítica do direito do consumidor. In: CAPAVERDE, Aldaci do Carmo; CONRADO, Marcelo. Repensando o direito do consumidor; 15 anos do CDC. Curitiba:OAB-PR, 2005 
FAVELA S/A . No mercado de favelas, há desde negócios mais sofisticados, como telefonia, à factoring que encobre agiotagem. O Globo Online. Rio de Janeiro, 23 ago. 2008. Disponível em : <http://oglobo.globo.com/rio/mat/2008/08/23> Acesso em: 26 nov. 2008.

FERNANDES, Edésio. Regularização dos assentamentos informais : o grande desafio dos municípios, da sociedade e dos juristas brasileiros. In: Regularização fundiária plena ; referências conceituais. Brasília: Ministério das Cidades, 2007.

Perspectivas para a renovação das políticas de legalização de favelas no Brasil.

FILOMENO, José Geraldo Brito. Código Brasileiro de Defesa do Consumidor: comentado pelos autores do anteprojeto. 5.ed. Rio de Janeiro: Forense Universitária, 1997

GOMES, Rosângela Maria de Azevedo. A usucapião coletiva: uma análise crítica do art. 10 da Lei $\mathrm{n}^{\circ} 10.257$ de 2001(Estatuto da Cidade).In:TEPEDINO, Gustavo; FACHIN, Luiz Edson. $O$ Direito \& o Tempo; embates jurídicos e utopias contemporâneas. Rio de Janeiro: Renovar, 2008.

GONDINHO, André Osório. Função social da propriedade. In: TEPEDINO, Gustavo(coord.)Problemas de Direito Civil-Constitucional. Rio de Janeiro: Renovar, 2000.

GRAU, Eros Roberto. A ordem econômica na Constituição de 1988. 8 ed.. São Paulo: Malheiros, 2003

LIRA, Ricardo Pereira. Elementos de Direito Urbanístico. Rio de Janeiro: Renovar, 1997.

Direito a moradia, cidadania e o estatuto da cidade. Revista Trimestral de Direito Civil. Rio de Janeiro, v.12, p.259-291, out./dez. 2002.

LOUREIRO, Francisco Eduardo. Usucapião individual e coletivo no Estatuto da Cidade. Revista Trimestral de Direito Civil. Rio de Janeiro, v.9, p.29, jan./mar. 2002

JAYME, Erik. Visões para uma teoria pós-moderna do direito comparado. Cadernos do Programa de Pós-Graduação em Direito da UFRGS. 2.ed. Tradução Claudia Lima Marques. Porto Alegre, v.1., ${ }^{\circ}$ 1, p.115-131, mar.2003.

MARQUES, Claudia Lima. Contratos no Código de Defesa do Consumidor. 4.ed. São Paulo: Revista dos Tribunais, 2004

Diálogo das Fontes. In: BENJAMIN, Antônio Herman; ; BESSA, Leonardo

Roscoe. Manual de Direito do Consumidor. São Paulo: Revista dos Tribunais, 2008

A Lei 8078/90 e os Direitos Básicos do Consumidor.In: ; 
MELlO, Marco Aurélio Bezerra de. Legitimação de posse dos imóveis urbanos e o direito de moradia. Rio de Janeiro: Lumen Juris, 2008.

MIRAGEM, Bruno. Direito do consumidor. São Paulo: Revista dos Tribunais, 2008

MONTEL, Alberto. La disciplina del possesso nel codice civile italiano. Torino: G.Giappichelli, 1946.

MUKAI, Toshio. O Estatuto da Cidade. São Paulo: Saraiva, 2001.

NEVES, Antônio Castanheira. Questão-de-facto-questão-de-direito ou o problema metodológico da juridicidade. Coimbra: Almedina, 1967.

PAMPLONA, Pablo Stolze. Controvérsias constitucionais acerca do usucapião coletivo. Revista Magister de Direito Civil e Processual Civil. São Paulo, v.12, p.37-42, maio/jun.2006

PERLINGIERI, Pietro. Perfis do Direito Civil. Tradução Maria Cristina de Cicco. Rio de Janeiro: Renovar, 1997.

POGREBINSCHI, Thamy. A questão fundiária na Favela da Rocinha. Revista Trimestral de Direito Civil. Rio de Janeiro, v.9, p.241-264, jan./mar.2002.

PONTES, Fernanda. Os mercadores da desilusão. Jornal O Globo. Rio de Janeiro, p.17, 27 ago. 2008.

RODOTÀ, Stefano. Persona-consumatore. In: STANZIONE, Pasquale. La tutela del consumatore tra liberismo e solidarismo. Napoli: Edizioni Scientifiche Italiane, 1999

SALEILLES, Raymond. La posesión. Tradução J.M.Navarro de Palencia. Madrid: Libraria General de Victoriano Suárez, 1909.

SALLES, José Carlos de Moraes. Usucapião de bens móveis e imóveis. 6. ed. São Paulo: Revista dos Tribunais, 2005.

SUNDFELD, Carlos Ari. O Estatuto da Cidade e suas Diretrizes Gerais. In: DALLARI, Adilson Abreu; FERRAZ, Sérgio. Estatuto da Cidade; comentários à Lei Federal 10.257/2001. São Paulo: Malheiros, 2003

TEPEDINO, Gustavo. Contornos constitucionais da propriedade privada. In: - Temas de Direito Civil. Rio de Janeiro: Renovar, 1999.

O Código Civil, os chamados microssistemas e a Constituição: premissas para uma reforma legislativa. In: .(coord.)Problemas de Direito Civil-Constitucional. Rio de Janeiro: Renovar, 2000.

VON IHERING, Rudolf. La posesión. Tradução Adolfo Posada. 2.ed. Madrid: Editorial Reus, 1926. 
